\title{
A young man with fever, dyspnoea and nonproductive cough
}

\author{
B. Balbi, F. Fabiano
}

\section{Case history}

A 19 year old male was admitted to our hospital because of fever $\left(39.5^{\circ} \mathrm{C}\right)$, dyspnoea with tachypnoea, and nonproductive cough. His past history was unremarkable. He was a mild smoker and denied use of drugs. Three days before admission, he had started to complain of fever and dry cough. He was given nonsteroidal anti-inflammatory drugs, but, since his shortness of breath was increasing, he decided to attend the Emergency Room of our hospital.

Physical examination revealed cyanosis, bibasilar crackles and tachycardia. A chest roentgenogram is shown in figure 1. Arterial blood gas measurements on room air were: arterial oxygen tension $\left(\mathrm{P}_{\mathrm{a}} \mathrm{O}_{2}\right) 7 \mathrm{kPa}$, arterial carbon dioxide tension $\left(\mathrm{Pa}_{1} \mathrm{CO}_{2}\right) 5.3 \mathrm{kPa}$ and $\mathrm{pH} 7.42$. Analysis of the patient's blood showed leucocytosis $\left(13.1 \times 10^{9}\right.$ cells $\left.\cdot \mathrm{L}^{-1}\right)$ with $87 \%$ neutrophils, $2.3 \%$ cosinophils, 7.1\% lymphocytes and $3.3 \%$ monocytes.

Fibreoptic bronchoscopy and bronchoalveolar lavage (BAL) were performed. Fibreoptic bronchoscopy showed no abnormality of the bronchial lumina, the presence of dense bronchial secretions, and an erythematous and fragile bronchial mucosa. The lavage cytological picture is shown in figure 2.

Correspondence: B. Balbi, Divisione di Pneumologia, Ospedale Sant'Andrea, Azienda USL 5 - Spezzino, 19100 La Spezia, Italy.

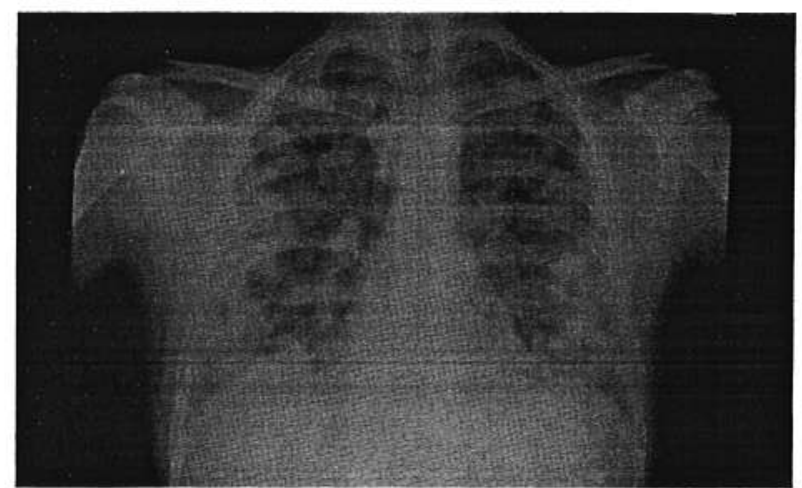

Fig. 1. - Posteroanterior chest roentgenogram.

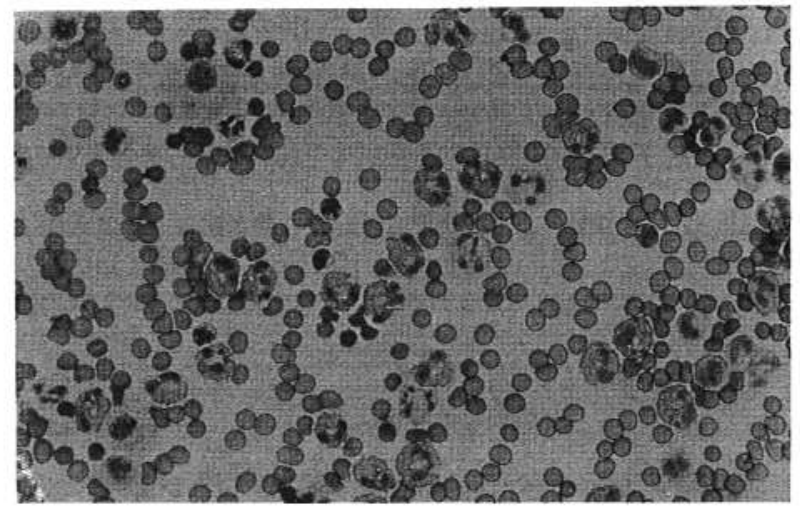

Fig. 2. - Bronchoalveolar lavage cytospin cell differential. (Diff-Quik). 


\section{Interpretation of fibreoptic bronchoscopy and BAL}

Chest radiographs showed diffuse bilateral pulmonary infiltrates, with patchy nodules particularly on the right lung. Total BAL cells were increased $\left(874 \times 10^{3} \cdot \mathrm{mL}^{-1}\right)$. There were many erythrocytes in the BAL samples because of fragility of the airway mucosa in contact with the tip of the bronchoscope. The differential BAL cell count was $30.5 \%$ macrophages, $3.5 \%$ Lymphocytes, $11 \%$ neutrophils and $55 \%$ eosinophils.

\section{TENTATIVE DIAGNOSIS: "Acute eosinophilic pneumonia"}

\section{Treatment and course}

The patient was treated with methylprednisolone pulse therapy (40 mg i.v. on Day 1) and supplemental oxygen. He improved rapidly, despite the occurrence on Day 5 of an eosinophil-rich pleural effusion. On Day 10 after admission, his white blood cell count was $14.3 \times 10^{9}$ cells $\mathrm{L}^{-1}$, with eosinophilia (38\%).

Serial microbiological and parasitological analysis of the patient's blood, stool, urine, bronchial secretions and BAL fluid, as well as a human immunodeficiency virus (HIV) blood test were negative. The proportions of peripheral blood and pleural fluid lymphocyte subpopulations were normal, although the percentages of CD25+, i.e. of activated T-lymphocytes, were increased in pleural fluid $(15 \%$ vs normal values in our laboratory ranging 2-7\%) and normal in peripheral blood. The levels of granulocyte-macrophage colony-stimulating factor (GMCSF) were higher in BAL fluid $\left(77 \mathrm{pg} \cdot \mathrm{mL}^{-1}\right)$ than in blood $\left(8 \mathrm{pg} \cdot \mathrm{mL}^{-1}\right)$.

The patient was discharged on Day 14 with no infiltrative shadow on chest roentgenogram. He had had no recurrence of disease 1 year after cessation of treatment.

\section{Discussion}

Acute eosinophilic pneumonia (AEP) is a clinical entity first described in $1989[1,2]$ and characterized by: 1) acute febrile illness; 2) hypoxaemic respiratory failure; 3) diffuse alveolar or mixed alveolar interstitial infiltrates on chest radiographs; 4 ) increased proportions ( $>25 \%$ ) of BAL eosinophils; 5) absence of parasitic, fungal or other infection; 6) prompt and complete response to corticosteroids; and 7) failure to relapse after discontinuation of corticosteroids [3].

The present patient fulfilled all of the above-mentioned criteria for the diagnosis of AEP. Although some patients with AEP have a history of atopic diseases [3, 4], many patients with AEP described in the literature have had no history of asthma or seasonal respiratory disorders or of atopy [2, 3, 5], as was the case for our patient. The roentgenographic picture of the case reported is typical of AEP, classically described as a mixture of alveolar and interstitial bilateral diffuse lung infiltrates. Computed tomography (CT) scan performed on Day 9 of the disease confirmed the presence of patchy infiltrates in both lungs and showed pleural effusion. The occurrence of pleural effusion is also characteristic of AEP. It is usually of moderate size and cytological examination shows increased proportions of eosinophils [4].

Eosinophils are, of course, the effector cells of this syndrome, and are, by definition, found in very high numbers in the alveolar spaces and in the lung interstitium $[4,6]$. AEP is one of the few diseases in which BAL, together with other clinicoradiological parameters, has a diagnostic value per se [2-5]. In our patient, BAL contained 480 eosinophils $\times 10^{3} \cdot \mathrm{mL}^{-1}$ of lavage fluid, i.e. values 2,000 times greater than those found in BAL of normal subjects [7], but consistent with previous reports of AEP patients $[2,4,5,8]$. In AEP, the presence of lungs crowded by eosinophils is in contrast, at least in the first few days of the disease, with the absence of blood eosinophilia [3-5]. On the day of bronchoscopy, our patient had a slight blood neutrophilia; thus, the BAL eosinophilia was not related to blood contamination of lavage fluid, despite the presence of erythrocytes in BAL fluid.

The diagnosis of AEP is considered to be a diagnosis of exclusion, since many other clinical conditions may present with acute respiratory failure, febrile illness and a BAL eosinophilia [3]. Syndromes somewhat similar to AEP have been described in patients with chronic myelogenous leukaemia and during postoperative respiratory failure $[3,6,9]$. In addition, many bacterial or viral pneumonias may present with an increase of BAL eosinophils, although not comparable to AEP. Also, fungal pneumonia, such as infection with Aspergillus or with Coccidioides, particularly in immunocompromised hosts, can resemble AEP. In our patient, examination of samples of BAL fluid and bronchial secretions for bacteria, acid-fast bacilli, fungi and $P$. carinii were all negative. Similarly, no microorganism was isolated from pleural fluid, from urine or in blood cultures. Parasites or their eggs were not found in the stools. Antibodies against clamydiae, mycoplasama, Legionella and Borrelia in serum were absent or of low levels. The Westem blot analysis of the antibodies against HIV components was negative, as was the assay for the antibodies or the viral components of hepatitis viruses $A, B$ and $C$.

The clinical course of AEP is also unique. Patients are known to improve dramatically over a few hours with pulse corticosteroid treatment, usually $60-125 \mathrm{mg}$ of methylprednisolone every $6 \mathrm{~h}$ until respiratory failure resolves [2-5]. Some patients improve spontaneously, without steroids [4]. Our patient received $40 \mathrm{mg}$ of methylprednisolone only once, and improved so quickly that supplemental oxygen was discontinued the next day. The efficacy of steroids in AEP may be explained by their ability to alter eosinophil adherence and chemotaxis.

The aetiology of AEP remains unknown, although a recent report showed that yeast can be the causative agent [10]. However, it has been suggested that AEP represents a pattern of acute hypersensitivity reaction in the lungs in response to inhaled antigens $[1,3,6]$.

Keywords: - Acute eosinophilic pneumonia, bronchoalveolar lavage. granulocytemacrophage colony-stimulating factor 


\section{References}

1. Badesch DB, King TE, Schwarz MI. Acute eosinophilic pneumonia: a bypersensitivity phenomeion? Am Rev Respir Dis 1989; 139: 249-252.

2. Allen JN, Patch ER, Gadek JE, Davis WB. Acute eosinophilic pneumonia as a reversible cause of noninfectious respiratory failure. $N$ Engl J Med 1989; 321: 569-574.

3. Allen JN, Davis WB. Eosinophilic lung diseases: state of the art. Am J Respir Crit Care Med 1994; 150: 1423-1438.

4. Ogawa H, Fujimura M, Matsuda T, Nakamura $H$, Kumabashiri I, Kitagawa S. Transient wheeze: eosinophilic bronchiolitis in acute eosiniphilic pneumonia. Chest 1993; 104: 493-496.

5. Okubo Y, Hossain M, Kai R, et al. Adhesion molecules on eosinophils in acute eosinophilic pneumonia. Am J Respir Crit Care Med 1995; 151: 1259-1262.
6. Davis WB, Wilson HE, Wall RL. Eosinophilic alveolitis in acute respiratory failure: a clinical marker for a noninfectious etiology. Chest 1986; 89: 7-10.

7. Balbi B, Aufiero A, Pesci A, et al. Lower respiratory tract inflammation in chronic bronchitis: evaluation by bronchoalveolar lavage and changes associated with treatment with Immucytal, a biological response modifier. Chest 1994; 106: 819-826.

8. Kita H, Sur S, Hunt LW, Edell ES, et al. Localized cytokine production and functional modulation of eosinophils in eosinophilic pneumonitis. Am J Respir Crit Care Med 1994; 149: A515.

9. St.John R, Allen JN, Pacht ER. Acute eosinophilc pneumonia as a cause of failure to wean from mechanical ventilation. Intensive Care Med 1990; 16: 408-410.

10. Miyazaki E, Sugisaki $\mathrm{K}$, Shigenaga $\mathrm{T}$, et al. A case of acute eosinophilic pneumonia caused by inhalation of Trichosporon terrestre. Am J Respir Crit Care Med 1995; 151: 541-543. 